\title{
A RESEARCH BASED CASE STUDY ON THE USE OF COMPETITIVE INTELLIGENCE TOOLS IN A MULTINATIONAL CORPORATION
}

\author{
Jennifer Breese-Vitelli, Middle Georgia State College, Jennifer.breesevitel@maconstate.edu \\ Fredrick G. Kohun, Robert Morris University, Kohun@rmu.edu
}

\begin{abstract}
With the growth of the global economy, organizations large and small are increasingly recognizing that competitive intelligence (CI) is essential to compete in industry. CI is used to gain an advantage in commerce and is useful for analyzing a company's strategic industry position. To remain current and profitable, organizations invest in new technologies to support CI needs; however, too few employees adequately utilize these technologies. Organizations that invest in new technologies and, in turn, use technologies to develop CI tools need to understand factors that influence utilization of those tools. This study provides industry and academia with information to assist in determining characteristics, specifically attitudes, which influence the frequency of employee CI tools usage. This research provides insight with regard to resource allocation for competitive intelligence tools and supporting technologies. Lastly, if other tools are being used to produce CI and are being developed outside the organization, expenditures made to support and develop tools within the company confines could decrease or become unnecessary.
\end{abstract}

Keywords: Information Technology (IT), Competitive Intelligence, Business Intelligence and Knowledge Management

\section{INTRODUCTION}

Competitive intelligence (CI) tools are developed in organizations both large and small; their purpose is to offer ways for management to maximize profits and stay competitive in a global economy where change is the only constant. Competitive intelligence tools are used for the collection of intelligence, analysis and communication/dissemination of both internal and external environmental factors. Azvine, Nauck, and Ho [2] suggested historically that data analysis through CI tools was used in business as mainly a reactive measure. However, the rapidity of change has necessitated that businesses turn data into information and quickly into action to maneuver past rivals in a complex business environment $[2,11,15]$.

Competitive intelligence is the culmination of both internal and external information. When accessing competitive intelligence, managers need a rigorous framework to avoid four pitfalls: reliance on intuition, being overtaken by emotion, optimism, and myopic thinking [8]. Additionally, challenges to enterprise-wide changes include moving away from a silo approach to more inclusive information management programs. The silo approach is one in which there is little integration and coordination within the organization; an enterprise-wide approach works to eliminate piecemeal approaches of information dissemination harbored by managers [5]. Infrastructure is not the only hindrance to more inclusive information management programs; $23 \%$ of Accenture respondents listed insufficient quantitative skills as the main challenge, while $36 \%$ indicated their companies have a shortage of analytic talent [15].

Competitive intelligence tools come in different forms, including: Commercial-Off-The-Shelf (COTS), custom software, and homemade tools. These tools are typically used in conjunction with each other in organizations. The inception of CI tools within an organization typically begins with homemade tools developed with the purpose of accomplishing a specific task. The CI process continues through the creation of several homemade tools that are task-specific. Some task-specific examples are forecasting sales, analyzing current sales, and determining productivity. When several homemade tools are being used by the organization, data becomes housed in a variety of different places [1]. Housing the data in various places perpetuates the silo effect. In order to consolidate data into forms where different people can use it, the organization usually makes a decision to purchase COTS as a lower cost alternative to customized software that is tailored to their specific business processes [1]. 


\section{Issues in Information Systems}

Volume 14, Issue 2, pp.419-428, 2013

Custom software could be purchased at a higher cost to better fit with current business processes or to begin standardizing new processes. Either type of software provides integration and serves the function of integrating disparate tools into one central location.

\section{Background}

The competitive intelligence definition used in this study was garnered through a review of the literature. Competitive intelligence (CI) is used to gain an advantage in commerce and is useful for analyzing a company's strategic position in the industry $[3,6,11]$. The definition of CI developed for use on the survey instrument was broad so as not to influence participants with regard to perceptions. Competitive intelligence involves the use of what is already known as a basis to find what is needed. The need to define the goal of an intelligence search is important in order to avoid information overload and develop strategy [6]. CI forms a close relationship of interdependence with strategic planning to steer the organization [10]. Knowledge management (KM), business intelligence (BI), and CI are a three-phase approach for companies to develop strategy. While the CI process is both internal and external, the information gathered as a result of competitive intelligence is more external to the organization. Investment in and development of CI is useless if its intended audience does not use it. Dishman and Calof [6] found that executives reported a strong CI culture; however, they are not really putting it into practice.

This comparative study suggests a broadened view of a concept typically only associated with the field of Knowledge Management (KM). The possibility exists to extend developments that have been made in a business with regard to the advent of the term knowledge worker by Drucker [7]. The three levels within the organization with knowledge workers at every level are: (1) KM as the first layer and core of the organization, (2) business intelligence as the second layer, and (3) competitive intelligence as the outer layer. A representation of the three organizational layers in which knowledge workers contribute to the organization is pictured in Figure 1.1.

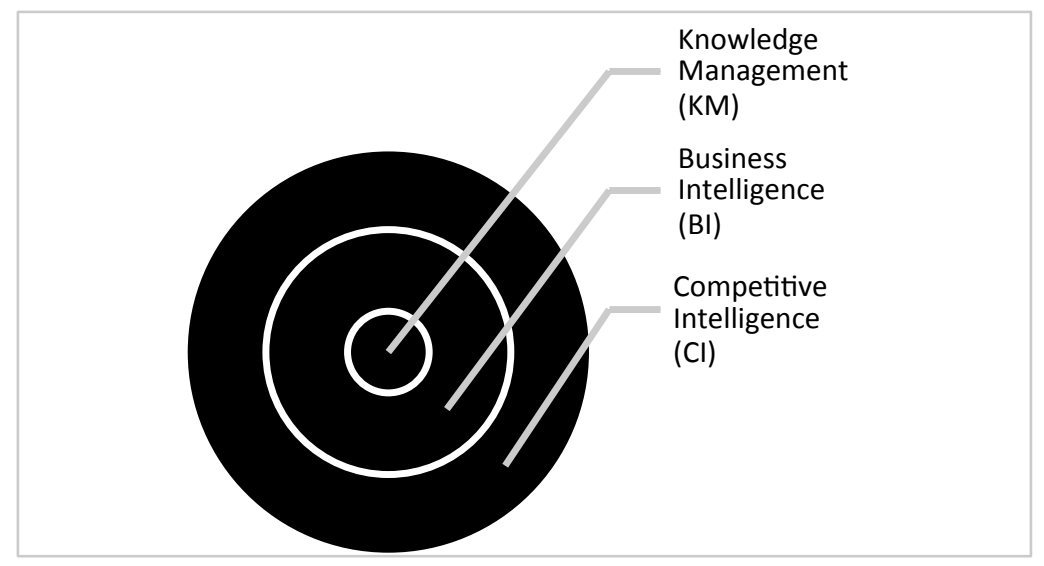

Figure 1.1 Three Layers of Knowledge Worker Contribution

Business Intelligence (BI) is a term coined by Gartner in early 1989, and it is comprised of two components [4]. The first component is an analytic process of convergence between internal and external data that, when combined, indicates goals the company should pursue. The second component is representative of "Online Analytical Processing (OLAP), querying or reporting, or data mining that provides different methods for flexible goal-driven analysis of business data, provided through a central data pool [14]. Seufert and Schiefer [14] stated that current data warehousing and approaches to BI are widely accepted at the decision support middle layer. Companies are empowering their employees to use BI to build queries in an efficient manner in order to provide better business information [4]. 


\section{Issues in Information Systems \\ Volume 14, Issue 2, pp.419-428, 2013}

This study used the ATCUS tool to compare computer attitudes to competitive intelligence tool usage because a previous research has assumed that a connection exists between a participant who has a higher computer usage score and, as a result, is expected to have an increased comfort level with computers and computer-related technologies thought literature does not support the assumption [16]. The operational definition of competitive intelligence for this study does not specify computer-related competitive intelligence tools but simply the term CI tools. The underlying construct of the term 'tool' implied that a tool was both company provided and computer-related and not something like a handout or physical newspaper. Therefore, it was believed, a high comfort level with computers and computer-related technologies would correlate to a higher frequency of CI tool usage.

\section{Study Overview}

There were two populations of participants in this study. The populations were sales employees at a single location of a multi-national transportation company and a second participant group representative of other industries. The convenience sample of transportation employee participants was compared to the second group whose responses were gathered through the social networks of co-researchers. This study could have implications as it relates to key information needs of end-users, deliverables, relationship management, sources of information, personnel and their training skills [9]. A comparative analysis was performed by examining the two populations overall, as well as intra-group, and inter-group comparisons. The problem of underutilization has intrinsic importance and affects people as individuals and organizations. Previous studies have not been completed to see if a relationship existed between increased attitude scores and any computer-related tool usage frequency. This study examined the issue in a business setting with a qualification that the participant was employed; responses by participants who were not employed were rejected and not considered in the analysis. Meaningful results were expected from the data for application in organizations with regard to resource allocation, human resources, and information flows. A quantitative method was chosen in order to draw generalizations about the population by taking a sample of that population and making claims based on the results.

\section{Research Questions}

To address the underutilization of costly competitive intelligence tools, which are necessary for companies to compete and get ahead in a changing global economy, this study addressed one overarching question: Does a relationship exist between computer attitudes and frequency of competitive intelligence tool usage? Additional subquestions were added to bring clarity to the data.

Research Question 1: Are there any differences in computer attitudes between low- and high-competitive intelligence tool users, respectively?

Research Question 2: Are there any correlations between the Attitudes Toward Computer Usage Scale and usage frequency of competitive intelligence tools by the participants?

Research Question 3: Are computer attitudes useful in predicting competitive intelligence tool usage for the population?

Research Question 4: Are available reports essential for participants' day-to-day activities?

Research Question 5: Are computer attitudes useful in predicting competitive intelligence tools usage for the population?

\section{Study Design}

This study explored whether a relationship exists between the computer attitudes of managers, non-managers and employees and their usage of competitive intelligence (CI) tools. Additional data questions included: participant demographics, CI usage frequency, a Likert Scale measurement of value, and an open-ended question to identify why participants view some CI tools as more important than others. 


\section{Issues in Information Systems \\ Volume 14, Issue 2, pp.419-428, 2013}

The survey was completed by two groups of participants. The first group of participants consisted of a convenience sample of employees in a sales department from a single location of a multinational transportation company. Coresearchers recruited the second group of participants through existing electronic lists including e-mail, LinkedIn, and Facebook. Co-researchers sent a communication to potential respondents requesting that they participate in a survey for a friend. Two co-researchers were identified as friends who reached out to other friends and colleagues through e-mail and social networking sites, such as LinkedIn and Facebook. The goal of collecting data in this manner was to reach a large and diverse group through a direct communication via their networks.

The data collection process began with the distribution of the survey instrument through e-mail to the convenience sample of sales employees at the multinational corporation (Group One). Personal e-mail addresses were used as the distribution method for non-exempt employees due to a strict company solicitation policy for employees that are considered to be hourly by the legal definition of their work. Non-exempt employees were solicited both in person and through the relationships of other non-exempt employees to obtain their e-mail addresses and explain the purpose of obtaining them. Then, either a study champion at the manager and/or director level distributed surveys to exempt employees through an e-mail to their work email addresses with the endorsement of their respective directors. The manager and/or director distributed the survey based on a Microsoft Outlook distribution list that sends other company-endorsed communications. The participant population was a broad range, aged 20-to-60years-old, due to a sample bias created through using the network of the researcher and the co-researchers.

\section{Data Gathering Instruments}

There was one data gathering instrument to which four demographic, four CI usage questions, and a definition of CI were added. The survey instrument was (ATCUS) v.2. The original ATCUS was developed by Popovich [13] and updated by Morris [12] to include questions based on technological advances that had occurred over the 22 years since its creation. The original study had 20 statements compared to 22 statements in the updated survey instrument; the statements were grouped into four factors or dimensions. The validity and reliability aspects of the instrument were tested in both of the studies.

\section{Analysis}

A data analysis was performed based on a spreadsheet downloaded from Survey Monkey in an Excel format, coded and uploaded into SPSS. Additionally, a review of the literature assisted in developing an explanation to determine whether a relationship exists between computer attitudes and usage of competitive intelligence tools. Several oneway Analysis of Variance (ANOVA) were conducted with an F-test and were to compare the means of two or more groups. The chi-square test was used to determine if a relationship between two variables existed. Pearson's Correlation was used to test for a linear relationship between two variables. The reliability analysis determined the cohesiveness of the scales to the current population. Lastly, a regression analysis was used to determine if a predictive relationship existed between the dependent variable and a group of independent variables.

\section{Study Overview}

\section{Participant Demographics and Characteristics}

The demographic questionnaire was comprised of two sections containing eight questions to learn the participants' background information. The first section was titled Background Information to Your Role at ABC Transportation Company for the first group of participants, and Background Information to Your Role in Industry for the second group of participants. Questions in section one included: age, sex, number of years employed by the company, and current job level.

The second survey section, titled Information Needs, began with a broad definition of competitive intelligence to assist respondents' understanding. 


\section{Issues in Information Systems}

Volume 14, Issue 2, pp.419-428, 2013

The study was comprised of a convenience sample of 47 transportation respondents (Group One) and 57 other industry respondents (Group Two). Two of the responses in Group Two were removed because one did not have a job in industry, and the second was a high school student. Table 1.1 is a combined statistical summary for both groups of participants (See Table 1.1).

Table 1.1

Demographics of combined participant groups

\begin{tabular}{lrlrrrr}
\hline Demographic & \multicolumn{2}{c}{ Number (missing) } & Mean & Std. Dev. & Min. & Max. \\
\hline & & & & & & \\
Age & 102 & $(2)$ & 39.75 & 10.49 & 22.00 & 69 \\
Gender & 104 & $(0)$ & 1.38 & 0.49 & 1.00 & 2 \\
Years employed at company & 103 & $(1)$ & 8.11 & 7.62 & 0.00 & 41 \\
Years in position & 103 & $(1)$ & 9.61 & 8.88 & 0.25 & 44 \\
Essential reports & 98 & $(6)$ & 1.74 & 0.72 & 1.00 & 3 \\
Value of CI tools & 82 & $(22)$ & 3.35 & 1.17 & 1.00 & 5 \\
& & & & & & \\
\hline
\end{tabular}

Research Question 1: What are the existing differences (if any) between groups' responses to survey questions?

Table 1.2

Demographics and Attitudes Toward Computer Usage

\begin{tabular}{|c|c|c|c|c|c|c|}
\hline & & $\mathbf{N}$ & Mean & $\begin{array}{l}\text { Standard } \\
\text { Deviation }\end{array}$ & $\mathbf{F}$ & Sig. \\
\hline \multirow[t]{3}{*}{ Age } & Transportation & 46 & 35.74 & 10.13 & 13.92 & 0.00 \\
\hline & Other Industries & 56 & 43.07 & 9.67 & & \\
\hline & Total & 102 & 39.76 & 10.49 & & \\
\hline \multirow[t]{3}{*}{ Years Employed at Company } & Transportation & 48 & 8.52 & 6.56 & 0.26 & 0.61 \\
\hline & Other Industries & 55 & 7.75 & 8.49 & & \\
\hline & Total & 103 & 8.11 & 7.62 & & \\
\hline \multirow[t]{3}{*}{ Number of Years in Position } & Transportation & 48 & 5.45 & 4.66 & 24.28 & 0.00 \\
\hline & Other Industries & 55 & 13.24 & 10.05 & & \\
\hline & Total & 103 & 9.61 & 8.88 & & \\
\hline \multirow[t]{3}{*}{ Are CI Tools Essential } & Transportation & 48 & 1.54 & 0.71 & 7.98 & 0.001 \\
\hline & Other Industries & 50 & 1.94 & 0.62 & & \\
\hline & Total & 98 & 1.74 & 0.72 & & \\
\hline \multirow[t]{3}{*}{ Value of CI Tools } & Transportation & 45 & 3.64 & 1.05 & 6.59 & 0.01 \\
\hline & Other Industries & 37 & 3.00 & 1.23 & & \\
\hline & Total & 82 & 3.35 & 1.17 & & \\
\hline \multirow[t]{3}{*}{ Computers as Tool Usage } & Transportation & 42 & 4.39 & 0.60 & 3.68 & 0.06 \\
\hline & Other Industries & 38 & 4.07 & 0.87 & & \\
\hline & Total & 80 & 4.24 & 0.75 & & \\
\hline \multirow[t]{3}{*}{ Confidence with Computers } & Transportation & 42 & 4.17 & 0.68 & 0.22 & 0.88 \\
\hline & Other Industries & 38 & 4.15 & 0.52 & & \\
\hline & Total & 80 & 4.16 & 0.60 & & \\
\hline \multirow[t]{3}{*}{ Negative Reactions to Computers } & Transportation & 42 & 1.96 & 0.58 & 1.81 & 0.18 \\
\hline & Other Industries & 38 & 2.18 & 0.94 & & \\
\hline & Total & 80 & 2.07 & 0.77 & & \\
\hline
\end{tabular}


Issues in Information Systems

Volume 14, Issue 2, pp.419-428, 2013

\begin{tabular}{lllllll}
\hline Positive Reactions to Computers & Transportation & 42 & 3.05 & 0.75 & 0.03 & 0.86 \\
& Other Industries & 38 & 3.08 & 0.88 & & \\
& Total & 80 & 3.06 & 0.81 & & \\
\hline Computer Attitudes & Transportation & 38 & 3.51 & 0.31 & 0.08 & 0.77 \\
& Other Industries & 32 & 3.48 & 0.42 & & \\
& Total & 70 & 3.50 & 0.36 & & \\
\hline
\end{tabular}

Table 1.2 displays statistically significant factors shaded light grey. Factors that are approaching significance are shaded dark grey, and the non-significant factors have no shading. Age, number of years in their position, reports viewed as essential, and the value of $\mathrm{CI}$ tools are all statistically significant at a $<.05$ level. The Computers as Tool Usage approached significance at $<.01$. The age of Group One was significantly different from the age of Group Two; Group One participants are significantly younger than respondents in Group Two. The numbers of years respondents have been in their positions are also significantly different among the samples. Group One respondents have been in their positions for a lesser period of time than respondents in Group Two. The responses to whether respondents find available CI tools to be essential to their day-to-day activities were also significant. Group One did find that CI tools more essential to their day-to-day activities than did Group Two. When questioned on the value they placed on CI tools, Group One found the tools to be more valuable than Group Two. Lastly, with regard to computers as tool usage on the ATCUS instrument, the responses approached statistical significance with Group One using them as a tool more often than Group Two. Research Question 2: Are there any differences in computer attitudes between low and high CI users,
respectively?

A two-way analysis of variance (ANOVA) yielded detailed results. Computer attitude scores were subjected to a two-way analysis of variance having two levels of usage (high, low). Neither of the usage levels was statistically significant at the .05 significance level.

\section{Combined Group of Participants}

ANOVA results indicated no significant statistical differences between daily and weekly CI usage on Computer Attitude $[\mathrm{F}(1,68)=0.028, \mathrm{p}=0.869]$ for the two groups of participants combined. Higher frequencies of CI usage do not indicate a higher computer attitude score, which would indicate a more positive view of computers overall. ANOVA results further indicated no significant statistical differences between weekly and monthly CI usage on computer attitude $[\mathrm{F}(1,68)=0.036, \mathrm{p}=0.850]$ for the combined groups. Again, CI usage does not indicate a higher computer attitude score.

\section{Transportation Group}

ANOVA results indicated no statistically significant differences between daily and weekly CI usage on Computer Attitude $[\mathrm{F}(1,36)=0614, \mathrm{p}=0.439]$ for Group One. High levels of CI tool usage frequency do not correlate to a higher computer attitude score.

ANOVA results also indicated no statistically significant differences between weekly and monthly CI usage on Computer Attitude $[\mathrm{F}(1,36)=0.792, \mathrm{p}=0.379]$. Low levels of $\mathrm{CI}$ tool usage frequency do not correlate to a higher computer attitude score.

\section{Other Industries Group}

ANOVA results indicated no significant statistical differences between daily and weekly CI usage on Computer Attitude $[\mathrm{F}(1,30)=0.185, \mathrm{p}=0.670]$ for Group Two. The results indicated that higher frequencies of CI tool usage do not correlate to a higher computer attitude score. Additionally, ANOVA results indicated no significant statistical differences between weekly and monthly CI usage on computer attitude $[\mathrm{F}(1,30)=0.017, \mathrm{p}=0.898]$. Therefore, frequencies of CI tool usage do not indicate a higher computer attitude score.

\section{Research Question 3: Are there any correlations between ATCUS score and usage frequency of CI tools}




\section{Issues in Information Systems \\ Volume 14, Issue 2, pp.419-428, 2013}

The results showed no significant relationship between the ATCUS and the frequency with which the groups use competitive intelligence tools. The data indicated a slightly negative correlation between ATCUS and the frequency of CI tool usage, but the correlation is not statistically significant. The overall ATCUS scores between the two groups were almost identical. However, the transportation group used competitive intelligence tools significantly more often, $71 \%$ to $25 \%$, to review the reports daily or multiple times per day. Group One scored higher in usage and confidence, while Group Two scored higher in positive and negative reactions.

\section{Research Question 4: Are available reports essential for participants' day-to-day activities?}

Both participant groups reported using CI tools more frequently if they also responded that CI tools were essential to their day-to-day activities. A number of respondents in both groups reported viewing CI tools in one of the high usage categories, but also responded that they were not essential to their day-to-day activities. More respondents from Group One reported viewing CI tools; although, they did not find them to be as essential as respondents in Group Two. There were nine participants in Group One who viewed tools with a frequency determined as high who did not find them essential, compared to four participants in Group Two who also viewed the reports with a high frequency level who did not find them to be essential to their day- to-day activities.

\section{Research Question 5: Are computer attitudes useful in predicting competitive intelligence tools usage for the population?}

A multiple regression analysis was used to develop a model to predict CI usage for future populations based on the scores produced by the ATCUS. The multiple logistic regression was used to develop a logistic regression model based on more than one predictor variable (Elliot \& Woodward, 2007). In the model, the dependent variable was frequency of tool usage, and the independent variables were the ATCUS instrument. The goal of the model was to accurately predict, based on the scores from ATCUS, frequency of participant CI tool usage as higher or lower. The creation of this model provided the possibility of providing predictability of the ATCUS to accurately predict CI tool usage among this population. Again, the variables in the model were Computers as Tool Usage, Confidence with Computers, Negative Reactions to Computers, and Positive Reactions to Computers. The degrees of freedom for Group One were assessed through measuring the number of participants $(\mathrm{N})$, subtracted by the number of variables $(\mathrm{k})$, minus one $(\mathrm{N}-\mathrm{k}-1=37)$. The degrees of freedom for Group Two were calculated in the same manner $(\mathrm{N}-\mathrm{k}$ $-1=33$ ). None of the scales for the ATCUS were significant in predicting frequency of CI tool usage, which was the case for both populations. While the model did not predict CI tool usage based on computer attitudes for this population, it is not safe to say that it would not for any other industry or population. The results of the regression analysis are located in Tables 1.3 and 1.4.

Table 1.3

Regression Model Predicting Tool Usage based on ATCUS - Group 1

\begin{tabular}{|c|c|c|c|c|}
\hline \multirow[b]{2}{*}{ Group 1 - Model } & \multicolumn{2}{|c|}{$\begin{array}{l}\text { Unstandardized } \\
\text { Coefficients }\end{array}$} & \multirow[b]{2}{*}{$\mathrm{T}$} & \multirow[b]{2}{*}{ Sig. } \\
\hline & $\mathrm{B}$ & Std. Error & & \\
\hline (Constant) & 4.28 & 2.08 & 2.06 & 0.05 \\
\hline Computers as Tool Usage & -0.41 & 0.58 & -0.71 & 0.49 \\
\hline Confidence with Computers & 0.68 & 0.5 & 1.30 & 0.20 \\
\hline Negative Reactions to Computers & 0.24 & 0.39 & 0.62 & 0.54 \\
\hline Positive Reactions to Computers & -0.23 & 0.30 & -0.76 & 0.45 \\
\hline
\end{tabular}

Table 1.4

Regression Model Predicting Tool Usage based on ATCUS - Group 2

\begin{tabular}{|c|c|c|c|c|}
\hline \multirow[b]{2}{*}{ Group 2 - Model } & \multicolumn{2}{|c|}{$\begin{array}{l}\text { Unstandardized } \\
\text { Coefficients }\end{array}$} & \multirow[b]{2}{*}{$\mathrm{t}$} & \multirow[b]{2}{*}{ Sig. } \\
\hline & $\mathrm{B}$ & Std. Error & & \\
\hline (Constant) & 1.56 & 3.42 & 0.46 & 0.65 \\
\hline
\end{tabular}




\section{Issues in Information Systems}

Volume 14, Issue 2, pp.419-428, 2013

\begin{tabular}{lllll} 
Computers as Tool Usage & 0.14 & 0.44 & 0.31 & 0.76 \\
Confidence with Computers & 0.14 & 0.83 & 0.17 & 0.87 \\
Negative Reactions to Computers & -0.27 & 0.40 & -0.67 & 0.51 \\
Positive Reactions to Computers & 0.42 & 0.43 & 0.96 & 0.34 \\
\hline
\end{tabular}

\section{Summary of the Results}

Some of the results were not surprising, with one example being that younger people were more likely to use competitive intelligence tools. Youth is often a factor in increased use and comfort levels with new and emerging technologies. There were two directional relationships that were notable and yet not statistically significant: the numbers showed movement but stopped short of a correlation. The first directional result was that higher computer attitude scores were indicative of lower frequency of usage of CI tools, as reported by participants. The second directional result produced a similar finding that was as a counterintuitive result. A large number of participants, relative to the sample, in Group One reported that they view CI tools on a regular basis, but also reported that they did not believe the tools were essential to their day-to-day activities. The same result was true for Group Two, but a lesser number of participants viewed the tools and then reported they were not essential to their day-to-day activities.

\section{Discussion of the Results}

The finding that young employees are viewing CI reports more often, while not surprising, could indicate other outside factors influencing viewing frequency. The identification that a high computer score does not relate to a high frequency of CI tools utilization was a surprise finding. The high computer score appears to have a negative correlation to the review of CI tools. The result that Group One and Group Two both had a number of participants who review CI tools, but do not find them to be essential seems to conflict with measures of value. The question becomes, if CI tools are not essential, why are the respondents viewing them with a high frequency?

\section{Interpretation of the Findings}

The revelation that younger participants view CI tools more often could be due to the fact that they have less volitional control and a lower social status in the organization with regard to the existence of other channels providing information. Additionally, younger participants are less likely than older participants to be managers. This fact continues the notion that they could be viewing the tools as dictated by their superiors. Managers and correspondingly older participants were less likely to use the tools, which could indicate that they are either using and/or creating their own tools, but they could also have a social network of peers allowing them to obtain the same information through other channels.

The finding that indicated participants who have higher computer usage scores also have a lower CI viewing frequency suggests multiple possibilities regarding other factors that could influence behavior, including, but not limited to: distrust of the technology, they are viewing and/or developing tools on their own due to their high level of computer usage, and, as previously mentioned, they may have developed social networks that provide the needed information through other channels. Trust in the technology relates back to consolidation, centralization, and timeliness of the information. While centralization of the information is desirable to the overall organization, it can cause problems for some individuals. Additionally, the timeliness of the information, once consolidation has occurred, could be another factor for reporting low usage levels. Information technologists develop specifications regarding the intervals at which the information will be updated, and those intervals often do not correspond with the frequency of need for the information. Technologists may determine the update frequency without input from the end-user. Technologists can be limited in their ability to pull the information at an interval that would increase frequency due to time constraints or misinformation with regard to the frequency of need by the end-user. The time intervals in which the information is available and updated are not always specified by technologists, and when they are specified, can further cloud the determination of usefulness to the end-user.

Additional possibilities that might influence low usage, as reported by the high computer attitude participants, could be the way the study itself was conducted. The internal construct of the survey was one in which the wording of the 


\section{Issues in Information Systems \\ Volume 14, Issue 2, pp.419-428, 2013}

survey referenced the internal CI tools. The survey heading in Group One referenced the transportation company, and in Group Two the reference to industry could have indicated to participants that only internal and organizationally-sanctioned CI tools were being measured. The more advanced group of computer users could be using CI tools outside of the confines of their companies, such as Hoovers, online business journals, Really Simple Syndication (RSS) feeds, meetings, and face-to-face conversations with experts, among other possibilities. A common misconception is that competitive intelligence capabilities are entirely dependent on information technology (Marin \& Poulter, 2004).

Two stages represented in Figure 1.2 illustrate participants who use CI tools frequently but do not find them essential in their day-to-day activities. Findings from respondents who review CI tools with a high level of frequency and respond that they do not find them as essential to their day-to-day activities suggest that the participants are progressing from taking the data-forming information without achieving the goal of knowledge and/or action as a result of engaging in the process. Again, Figure 1.2 illustrates the stages of taking data and forming knowledge as also associated with actionable strategy.

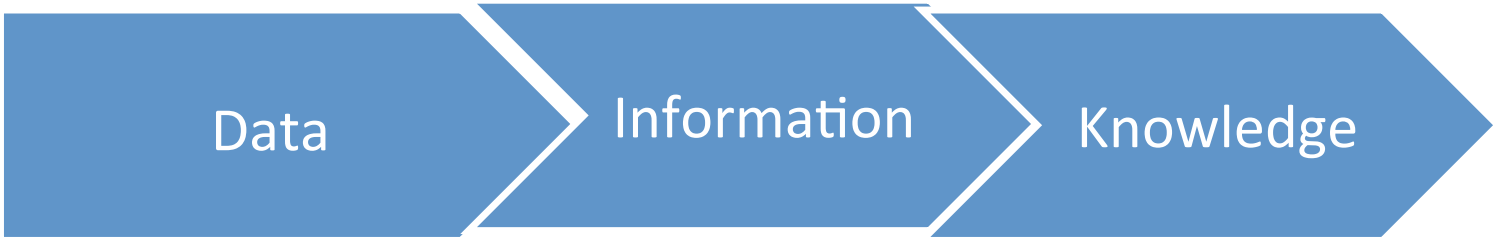

Figure 1.2 Stages of Respondent Understanding of CI Information

\section{CONCLUSIONS}

Competitive Intelligence (CI) is essential to compete in industry; therefore, understanding CI tool usage is critical to many areas of decision-making. This quantitative study used the Attitudes Toward Computer Usage Scale (ATCUS) survey instrument to determine if attitudes influenced CI tool usage for two populations of adult employees. The major finding was counterintuitive and suggested that a higher ATCUS was related to lower levels of CI tool usage. The findings were a supported several fields that lack literature on the subject. Future studies should employ a qualitative approach to determine sources of competitive intelligence outside of tool usage and to clarify the construct of how participants view internal versus external tools.

\section{REFERENCES}

1. Andriole, S. J. (2006). The collaborate/integrate business technology strategy. Communications of the $A C M, 49(5), 85-90$.

2. Azvine, B., Nauck, D., \& Ho, C. (2003). Intelligent business analytics - a tool to build decision-support systems for eBusinesses. BT Technology Journal, 21(4), 65-71.

3. Bernhardt, D. (1994). I want it fast, factual, actionable - tailoring competitive intelligence to executives needs. Long Range Planning, 27(1), 12-24.

4. Chou, D., Chou, A., \& Tripuramallu, H. (2005). BI and ERP integration. Information Management \& Computer Security, 13(5), 340-349.

5. Davenport, T. H., Harris, J. G., \& Morison, R. (2010). Analytics at Work: Smarter Decisions, Better Results. Boston, Massachusetts: Harvard Business Press.

6. Dishman, P., \& Calof, J. (2007). Competitive intelligence: a multiphase precedent to marketing strategy. European Journal of Marketing, 42(7/8), 766-785.

7. $\quad$ Drucker, P. F. (1959). Landmarks of tomorrow ([1st ed.). New York: Harper.

8. Gilad, B. (2009). Business war games: how large, small, and new companies can vastly improve their strategies and outmaneuver the competition. Franklin Lakes, NJ: Career Press.

9. Heppes, D. (2008, April 22). DigiSpace at the University of Johannesburg: An assessment of the level of maturity of the competitive intelligence function within a South African retail bank. UJDigiSpace. Retrieved March 2, 2010, from http://hdl.handle.net/10210/260

10. Liebowitz, J. (2006). Strategic intelligence: business intelligence, competitive intelligence, and knowledge 


\section{Issues in Information Systems}

Volume 14, Issue 2, pp.419-428, 2013

management. Boca Raton, FL: Auerbach Publications.

11. Lonnqvist, A., \& Pirttimaki, V. (2006). The measurement of business intelligence. Information Systems Management, 23(1), 32-40.

12. Morris, S., Gullekson, N., Morse, B., \& Popovich, P. (2009). Updating the attitudes toward computer usage scale using American undergraduate students. Computers in Human Behavior, 25(535), 543.

13. Popovich, P., Hyde, K., Zakrajsek, T., \& Blumer, C. (1987). The Development of the Attitudes Toward Computer Usage Scale. Educational and Psychological, 47, 261-269.

14. Seufert, A., \& Schiefer, J. (2005). Enhanced Business Intelligence - Supporting Business Processes with Real-Time Business Analytics. Sixteenth International Workshop on Database and Expert Systems Applications proceedings : 22-26 August 2005, Copenhagen, Denmark. (pp. 919-925). Los Alamitos, California: IEEE Computer Society.

15. Todd, G. (2009). The imperative of analytics; Accenture survey shows executives view analytics as key to staying competitive. Information Management, 19(2), 44.

16. Winter, S., Chudoba, K., \& Gutek, B. (1998). Attitudes toward computers: when do they predict computer usage? Information and Management, 34, 275-284. 